\title{
How Many Levels Within the Enterprise Should have Measurement Metrics and Why? What are the Essential Elements in Defining and Selecting Kpis and Why?
}

\section{Payal Chadha*}

Swiss Management Center University Zug, Kuwait

\section{Introduction}

Enterprise Resource Planning (ERP) software systems join key business and management procedures inside and outside a firm's boundary [1]. Multi-firm ERP implementation and financial data demonstrate higher performance across a wide range of financial metrics. Shortly after the implementation, the speed of the business performance and productivity reduces. As a result, the financial markets constantly reward the adopters with higher market valuation.

ERP serves numerous industries and various serviceable areas in an integrated fashion, attempting to computerize operations such as supply chain management, inventory control, manufacturing scheduling and production, sales support, customer relationship management, financial and cost accounting, human resources, and other data-oriented management process.

\section{Levels of Measurement Metrics}

Taticchi et al. [2] suggested that a comprehensive performance measurement and management system should comprise of five systems:

1. Performance system - Complex enterprise-scale systems are considered to be time criticall, where the feature of performance becomes a significant functional aspect and needs to be provable Adam [3];

2. Cost system - Firms must develop worldwide strategies to coordinate their operations at all phases of the value-adding chain by examining ways to reduce costs, shorten product development times and manage risks [4]. Supply chain management aims to reduce costs, risks and lead times associated with these transactions, thus releasing value. An enterprise cost management approach puts together cost management and profitability analysis for all levels in the company and triumphs over challenges [4];

3. Capability evaluation system - The structure comprises of seven elements that form a management system approach to fostering fundamental innovation O'Connor [5] (1) particular organization structure; (2) interface mechanisms with the mainstream organization, some of which are tightly coupled and others of which are loose; (3) exploratory processes; (4) mandatory skills and talent development; (5) governance and decision-making mechanisms at the project; (6) suitable performance metrics; and (7) Suitable culture and leadership perspective [5];

4. Benchmarking system - process of comparing one's performance to the statistics of a group of competitors, which is a common and important process for important business metrics, called key performance indicators (KPI) [6]. Several secure multi-party computation protocols for securely and privately computing the statistics of KPIs have been developed as the information is sensitive; and

5. Planning system - provides the combined business function to the organization by incorporating the core processes [7]. It is becoming highly vulnerable and confidential, where the security is vital for its operation. ERP vendors have integrated their security solution, which may work internally; but in an open environment, new technical approaches to secure an ERP system are required [7].

As defined in earlier units, KPIs help companies achieve their objectives by defining and measuring progress. Once identified, it is necessary to set up and build up a systematic approach to supervise and assess its progress towards those predetermined objectives, e.g. the price of oil maybe a crucial factor for the performance of a business, but cannot use as a KPI since the business has no control or power to directly change it. By contrast, the exposure to high fluctuations in oil prices can be controlled and be used as a KPI. Improper selection of KPI metrics can result in significant prevention of business strategy, employee's dissatisfaction, or completely drowns a performance management initiative [8].

\section{Characteristics and Criteria of KPI}

Eckerson described the characteristics of "good" KPIs. According to his study, effective KPIs are: Bare: Fewer the better, Piercer: Users can pierce through the details, Easy: Users understand the KPI, Actionable: Users know how to influence the outcomes, Owned: KPIs are possessed by the owner, Referenced: Users can view origins and context, Interrelated: KPIs drive desired outcomes as they are related and connected to one another, Balanced: KPIs consist of both financial and non-financial metrics, Aligned: KPIs don't damage each other, and Authenticated: Workers can't dodge the KPIs. Hursman [9] defined five criteria for effective KPIs: Specific - pertinent to firm's objectives, Measurable -categorize metrics for each KPI, Attainable - collecting actual data to accomplish each metric in KPI, Realistic - by converting the metrics into scorecards, and Time bound - scorecards reach the users in timely manner (SMART). Laidlaw [10] states that KPIs provide Centrica Group a way of vigorously measuring the progress over the long term.

\section{Conclusion and Challenges}

Organisations are encouraged to improve the quality using three drivers: professionalism - a profession establishes and maintains standards through a system of governance, regulation - the government and independent regulators establish standards which everyone must

*Corresponding author: Chadha P, Swiss Management Center University Zug Kuwait, Tel: +96569078096; E-mail: payal.chad@gmail.com

Received May 10, 2016; Accepted May 31, 2016; Published June 02, 2016

Citation: Chadha P (2016) How Many Levels Within the Enterprise Should have Measurement Metrics and Why? What are the Essential Elements in Defining and Selecting Kpis and Why? Int J Account Res 4: 132. doi:10.4172/2472-114X.1000132

Copyright: $\odot 2016$ Chadha P. This is an open-access article distributed under the terms of the Creative Commons Attribution License, which permits unrestricted use, distribution, and reproduction in any medium, provided the original author and source are credited. 
Citation: Chadha P (2016) How Many Levels Within the Enterprise Should have Measurement Metrics and Why? What are the Essential Elements in Defining and Selecting Kpis and Why? Int J Account Res 4: 132. doi:10.4172/2472-114X.1000132

comply resulting in increase in the quality of services, and market forces - consumers influence improvement in quality and safety by selecting those organisations that have desirable quality and safety record. The objectionable behaviors that come into sight due to the in appropriate use of metrics can lead organizations to failure [11]. A challenge is whether the KPIs presented to the Board are those that allow them to assess progress against stated strategies, and when reported externally, allow readers to make a similar assessment. If not, is this because the information is simply not available or because it is not yet escalated to the Board but instead be assessed by management of individual business units? [12]. Appropriate use for metrics is necessary for linking each measure to a goal understood by everyone. Organizations using metrics understand the value in watching the trends, monitoring in smaller periods to understand individual, management and organizational influences. It is important to understand when measures are no longer applicable, replace them, or drop them as progress is made towards the goal and the environment changes around it.

\section{References}

1. Hitt LM, Wu DJ, Zhou X (2002) Investment in enterprise resource planning business impact and productivity measures. Journal of Management Information Systems 19: 71-98.

2. Taticchi P, Balachandran K, Tone F (2012) Performance measurement and management systems: state of the art, guidelines for design and challenges. Measuring Business Excellence 16: 41-54
3. Adam L (2012) Performance verification in complex enterprise-level component systems. Formal Aspects of Component Software Lecture Notes in Computer Science pp: $286-289$

4. Gunasekaran A, Williams HJ, McGaughey RE (2005) Performance measurement and costing system in new enterprise. Technovation 25: 523-533.

5. O'Connor GC (2008) Major innovation as a dynamic capability: a systems approach. The Journal of Product Innovation Management 25: 313-330.

6. Kerschbaum F (2008) Building a privacy-preserving benchmarking enterprise system. Enterprise Information Systems 2: 421-441.

7. She W, Thuraisingham B (2007) Security for enterprise resource planning systems. Information Systems Security 16: 152-163.

8. Iveta G (2012) Human resources key performance indicators. Journal of competitiveness 4: 117-128.

9. Hursman A (2010) Measure what matter. Information management.

10. Laidlaw S (2008) Measuring our Performance. Annual Report and Accounts 2008.

11. Fowler M (2013) An appropriate use of metrics. Health Information and Quality Authority. Guidance on developing key performance indicators and minimum data sets to monitor healthcare quality.

12. AJ H (2015) The Most difficult elements of establishing and launching a management performance measurement system. Journal of Entrepreneurship and Organization Management. 